\title{
Sensitivity and Specificity of Portable Hearing Screening in Middle-Aged and Older Adults
}

\author{
Carolina Louise Cardoso ${ }^{1}$ Ângelo José Gonçalves Bós ${ }^{2}$ Andréa Krüger Gonçalves ${ }^{3}$ \\ Maira Rozenfeld Olchik ${ }^{4}$ Leticia Sousa Flores ${ }^{1}$ Bruna Macagnin Seimetz ${ }^{1}$ Magda Aline Bauer ${ }^{1}$ \\ Patricia Pérez Coradini ${ }^{5}$ Adriane Ribeiro Teixeira ${ }^{6}$
}

\footnotetext{
${ }^{1}$ Universidade Federal do Rio Grande do Sul, Porto Alegre, RS, Brazil

${ }^{2}$ Geriatrics and Gerontology Institute, Pontifícia Universidade Católica do Rio Grande do Sul, Porto Alegre, RS, Brazil

3 Department of Physical Education, Universidade Federal do Rio

Grande do Sul, Porto Alegre, RS, Brazil

${ }^{4}$ Department of Surgery and Orthopedics, Universidade Federal do

Rio Grande do Sul, Porto Alegre, RS, Brazil

${ }^{5}$ Comunicare Hearing Aids, Porto Alegre, RS, Brazil

${ }^{6}$ Department of Developmental Psychology and Personality,

Universidade Federal do Rio Grande do Sul, Institute of Psychology,

Porto Alegre, RS, Brazil.
}

Int Arch Otorhinolaryngol 2014;18:21-26.

\begin{abstract}
Address for correspondence Adriane Ribeiro Teixeira, Department of Developmental Psychology and Personality, Federal University of Rio Grande do Sul, Rua Ramiro Barcelos, 2600, Instituto de Psicologia da UFRGS, Porto Alegre, Rio Grande do Sul 90035003, Brazil (e-mail: adriane.teixeira@gmail.com).
\end{abstract}

\begin{abstract}
Keywords

- hearing

- mass screening

- audiology

- older adult

- gerontology

Introduction Hearing screening allows the identification of individuals with hearing loss.

Aim To determine the sensitivity and specificity of a portable hearing screening device in middle-aged and older adults using the manufacturer scoring and a scoring system proposed by the researchers.

Methods In this transversal study, participants underwent anamnesis, otoscopy, and hearing screening using portable equipment. After this, a pure tone audiometry was performed, with participants classified into two groups: with and without hearing loss. The sensitivity and specificity of the hearing screening were calculated for the right and left ears using two methods of interpretation: the original method recommended by the manufacturer (criteria 1) and the method proposed by researchers (criteria 2 ).

Results The sample consisted of 55 individuals, 83.6\% $(n=46)$ of whom were women. Per criteria 1, the sensitivities were 26.3 (right ear) and $21.4 \%$ (left ear). The specificity was $100 \%$ for both ears. Using criteria 2, the sensitivity was 94.7 (right ear) and 100\% (left ear). The specificity was 74.3 (right ear) and 65.9\% (left ear).

Conclusion This study showed that the criteria proposed by the manufacturer presented low sensitivity in the hearing screening. The criteria proposed by the researchers to achieve a more efficient performance reached high and balanced values for sensitivity and specificity.
\end{abstract}

\section{Introduction}

Aging causes a series of changes in the body. As in other organs, the first changes in the functioning of the auditory system can be observed around 30 to 40 years, and these changes intensify over time. Hearing loss due to aging is called presbycusis ${ }^{2-4}$; it has a high prevalence among the older adult population and can cause several social difficulties due to the communication disturbances it entails. ${ }^{5-8}$ received

September 4, 2013

accepted

September 6, 2013
DOI http://dx.doi.org/

10.1055/s-0033-1358660. ISSN 1809-9777.
Copyright ( $\odot 2014$ by Thieme Publicações License terms Ltda, Rio de Janeiro, Brazil

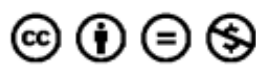


The consequences of hearing loss may vary according to the type, degree, and age of onset. Adults and older adult persons generally present with mild to moderate sensorineural hearing loss, $2,4,6,9,10$ which can lead to isolation and restrict participation in social and family life, often as an effort to avoid becoming the subject of ridicule or contempt. ${ }^{11}$ Hearing loss can also be associated with cognitive impairment, depression, and reduced functional status and quality of life. ${ }^{5,7,8,12-16}$

The diagnosis and early intervention, as well as the implementation of a hearing reeducation program specific to the population of adults and older adults, are key issues to improve quality of life for this population and, consequently, enable them to enjoy a better family life and social integration. ${ }^{3,4,8,17-19}$ In presbycusis, however, as the hearing loss occurs gradually and progresses slowly, ${ }^{4,20,21}$ and it often goes unnoticed or is denied by individuals during its early stage. ${ }^{3,11}$ Therefore, hearing screening should be a standard procedure in hospitals, health centers, and clinics, with the aim of quickly, easily, and inexpensively testing a large number of individuals, thus enabling early diagnosis and treatment and decreasing the consequences of hearing deprivation. $5,10,17,18,20,22$ This procedure, however, is still not commonly used by professionals working with adults and older adults. ${ }^{23}$ In Brazil, the most commonly used method to detect hearing loss is the complete audiometric evaluation, which requires a soundproof booth, and thus it is not accessible as a screening tool.

Currently, screening can be performed by means of standardized questionnaires ${ }^{10}$ or by undertaking simplified hearing tests, not intended to determine hearing thresholds but rather to identify the possibility of an individual presenting hearing loss. ${ }^{24}$ Recently, a piece of portable equipment for hearing screening that can be used on individuals of different age groups has been launched in Brazil. It is designed for use in quiet environments and does not require an audiometric booth. The operation of the device is extremely simple and does not cause any discomfort to the patient. Subjects are instructed to pay attention and signal every sound they hear by raising their hand. A positive test indicates that the subject should undergo a complete audiological evaluation, according to the device's user manual. ${ }^{25}$

Given the nonexistence of similar devices in the Brazilian market and the lack of a theoretical framework on the subject, this study aims to verify the device's ability to discriminate between middle-aged and older adults with or without mild or moderate hearing loss, using two interpretation criteria: the one recommended by the manufacture's manual (criteria 1) and the one proposed by the authors of this study (criteria 2).

\section{Materials and Methods}

This cross-sectional, observational, comparative study had a sample consisting of both men and women participating in university outreach projects, aged 45 years or older. The study was initiated after participants had signed the informed consent form.
According to the norms established for human research, this study was reviewed and approved by the Research Ethics Committee of the Institute of Psychology of the Universidade Federal do Rio Grande do Sul (under registration number 22229). Subjects included individuals who, at the time of data collection, presented with wax obstructing their ear canal, either unilaterally or bilaterally, identified by visual inspection of the ear canal; outer ear pathologies; cholesteatoma; or chronic suppurative otitis media (identified by a medical report or through information provided by the subject).

After signing the informed consent form, the individuals answered a sociodemographic questionnaire consisting of questions related to hearing, tinnitus, and earache. After this, participants underwent a meatoscopy using a WelchAllyn (New York, USA) brand otoscope. The hearing screening and pure tone audiometry were then conducted.

The hearing screening was performed using the HearChek Screener equipment from Siemens (Munich, Germany) in a quiet environment, with noise levels under 50-dB SPL (sound pressure level) as per the guidelines in the device's user manual. ${ }^{25}$ The environmental noise level was checked using the Manaus DL-4020 sound pressure meter (Manaus, Brazil). The subjects were instructed to signal every time they heard a sound. The machine produces a sequence of three sounds at the frequency of $1,000 \mathrm{~Hz}$ (55-, 35-, and 20-dB hearing level [dBHL]) and three other sounds in the frequency of $3,000 \mathrm{~Hz}(75,55$, and $35 \mathrm{dBHL})$. Results were recorded in a specific form, indicating the number of times and the intensities at which the individual perceived the sound. According to the equipment's user manual, individuals who perceived more than three sounds were considered to have "passed" the screening, whereas individuals who heard less than three sounds in each ear were considered to have "failed" (criteria 1 ).

Because two of proposed sounds ( 35 and $20 \mathrm{dBHL}$ at 1,000 $\mathrm{Hz}$ ) fall in the normal hearing threshold, the authors of this work decided to test also different criteria: the participant was considered to have failed the screening if they did not hear five of six sounds. Therefore, individuals who perceived at least five of the sounds presented in each ear were considered to have "passed" (criteria 2).

The pure tone audiometry was conducted in an acoustically treated booth. Tone thresholds were tested by air conduction from 250 to $8,000 \mathrm{~Hz}$ and by bone conduction from 500 to 4,000 Hz. An AD 229e audiometer (Denmark) was used, with TDH-39 (USA) headphones. The degree of hearing loss was classified by finding the mean of the thresholds obtained at the frequencies of $500,1,000,2,000$, and 4,000 $\mathrm{Hz}$. Mean values equal to or under $25 \mathrm{dBHL}$ indicated normal hearing; mean values between 26 and $40 \mathrm{dBHL}$ indicated mild hearing loss; mean values between 41 and $60 \mathrm{dBHL}$ indicated moderate hearing loss; mean values between 61 and $80 \mathrm{dBHL}$ indicated severe hearing loss; and mean values over $81 \mathrm{dBHL}$ indicated profound hearing loss. ${ }^{26}$ After the examinations had been performed, the sensibility (percent of true-positive tests) and specificity (percent of truenegative test) were calculated for both criteria.

We chose to include only subjects with normal hearing thresholds and mild to moderate hearing loss in the study, 
because they represent more significantly the effects of aging on hearing. As described earlier, most of the individuals in the age group under study presented with these degrees of hearing loss. $2,4,6,9,10$

\section{Statistical Analysis}

The data analysis initially approached descriptive statistics, with the distribution of simple and relative frequencies, as well as mean, standard deviation, and range, and the symmetry was investigated using the Kolmogorov-Smirnov test.

For greater statistical robustness in the research, the nonparametric Kruskal-Wallis test was performed to check if the discriminatory accruals were significantly different, because this test does not require observing the assumptions of the previous tests.

To evaluate the accuracy of the screening tests for the diagnosis of hearing loss, calculations of sensitivity, specificity, positive predictive value, and negative predictive value were performed using the result of the pure tone audiometry as the gold standard, through the McNemar test.

Data were treated statistically using the Statistical Package for Social Sciences for Windows 17.0 software (USA) and, for decision criteria, a significance level $(\alpha)$ of $5 \%$ was adopted.

\section{Results}

The sample consisted of 55 subjects, with a mean age of $65.3 \pm 8.4$ years, with ages ranging between 48 and 85 years. Of the total of study participants, $20.0 \%(n=11)$ were between 48 and 59 years, $52.7 \%(n=29)$ were between 60 and 69 years, and 27.3\% $(n=15)$ were between 70 and 85 years. The majority of the group under study were females, accounting for $83.6 \%(n=46)$ of the sample.

There was a predominance of normal hearing thresholds $(p<0.001)$ in both the right ear $(64.8 \%)$ and the left ear (74.5\%; - Table 1).

To analyze the use of the screening equipment regarding sensitivity and specificity in terms of detecting hearing loss, the result of the audiometry was defined as the gold standard.

Table 1 Absolute and relative distribution of hearing classification for the right ear and left ear

\begin{tabular}{|c|c|c|}
\hline \multirow[t]{2}{*}{ Variables } & \multicolumn{2}{|c|}{ Total } \\
\hline & $n$ & $\%$ \\
\hline \multicolumn{3}{|c|}{ Right ear hearing classification ${ }^{a}$} \\
\hline Normal (0-25 dBHL) & 35 & 64.8 \\
\hline Mild (26-40 dBHL) & 15 & 27.8 \\
\hline Moderate (41-60 dBHL) & 4 & 7.4 \\
\hline \multicolumn{3}{|l|}{ Left ear hearing classification ${ }^{a}$} \\
\hline Normal (0-25 dBHL) & 41 & 74.5 \\
\hline Mild (26-40 dBHL) & 7 & 12.7 \\
\hline Moderate (41-60 dBHL) & 7 & 12.7 \\
\hline
\end{tabular}

Abbreviation: $\mathrm{dBHL}$, decibel hearing level.

${ }^{a}$ There was a loss by nonresponsiveness in the right ear evaluation.
Accordingly, the results of the equipment were tested against the audiometry classification. Data were analyzed for each ear separately, so as to more accurately identify the probability of pass or fail.

According to the results presented in - Table 2, for the right ear, it was found that the screening had a very low sensitivity using criteria 1 , reaching a value of only $26.3 \%$. Of the 19 ears identified as having hearing loss, 14 passed the screening. Specificity, in turn, was $100 \%$ (i.e., all ears classified as having normal hearing passed the screening). When using criteria 2 , there was an increase in sensitivity (94.7\%; i.e., of the 19 ears with hearing loss, 18 failed the screening). Sensitivity, however, decreased from 100 to $74.3 \%$. Of the 35 right ears with normal hearing, 26 passed the screening (-Table 2 )

- Table 3 presents the results of the hearing screening in the left ear. Using criteria 1, sensitivity values were extremely low, at only $21.4 \%$. Thereby, of the 14 ears with hearing loss, only three failed the screening. Specificity was at $100 \%$ ( i.e., all ears with normal hearing passed the screening). With the use of criteria 2 , sensitivity was at $100 \%$ (i.e., all the ears diagnosed with hearing loss failed the screening). Specificity, however, decreased to $65.9 \%$. Thus, of 41 ears with normal hearing, only 27 passed the hearing screening (-Table $\mathbf{3}$ ).

\section{Discussion}

This study aimed to verify the sensitivity and specificity of hearing screening in middle-aged adults and older adults with or without mild to moderate hearing loss, when compared with a pure tone audiometry (gold standard). Studies have underscored the screening as an important hearing care activity, because it enables early diagnosis and intervention in adults and older adults. ${ }^{7,8,18,22,23,27-31}$

This study showed a sample made up mostly of females (83.6\%). This factor may be related to the greater number of women in the studied age group, ${ }^{9,32-34}$ as well as to a more effective presence of the female gender in group activities and to a more active lifestyle, ${ }^{33}$ because the population under study attends university outreach activities.

A significant number of individuals had hearing classified as normal (64.8\% for right ear and $74.5 \%$ for left ear). Mild (27.8\% right ear and $12.7 \%$ left ear) to moderate $(7.4 \%$ right ear and $12.7 \%$ left ear) cases of hearing loss were also observed in the sample. The literature shows similar results to those found in this work, because one of the characteristics of presbycusis is mild to moderate hearing loss. 2,4,6,9,10

Mild hearing loss is not regarded as disabling, because it allows individuals to perceive most environmental sounds. Moderate hearing loss, on the other hand, can incapacitate an individual for adequate social life. ${ }^{26}$ It should be noted, however, that even mild hearing loss hinders the perception of consonant sounds that are important to proper speech recognition and discrimination, thus causing communication disturbances that can lead to social isolation and alienation from the family. Therefore, even mild hearing loss should be identified, and individuals suffering from it should be referred for rehabilitation. 
24 Portable Hearing Screening in Middle-Aged and Older Adults Cardoso et al.

Table 2 Analysis of responses to hearing screening in right ear, considering the interpretation according to criteria 1 and 2

\begin{tabular}{|c|c|c|c|c|}
\hline & \multirow[t]{2}{*}{ Total } & \multicolumn{2}{|c|}{ Right ear hearing classification } & \multirow[t]{2}{*}{$p$} \\
\hline & & Normal hearing & Hearing loss & \\
\hline \multicolumn{5}{|l|}{ Criteria 1} \\
\hline Passed & $49(90.7 \%)$ & 35 & 14 & \multirow[t]{2}{*}{$<0.001^{\mathrm{a}}$} \\
\hline Failed & $5(9.3 \%)$ & 0 & 5 & \\
\hline Total & $54(100 \%)$ & $35(64.8 \%)$ & $19(35.2 \%)$ & \\
\hline \multicolumn{2}{|c|}{ Sensitivity/specificity (\%) } & \multicolumn{3}{|c|}{$26.3 / 100$} \\
\hline \multicolumn{5}{|c|}{ Criteria 2} \\
\hline Passed & $27(50 \%)$ & 26 & 1 & \multirow[t]{2}{*}{$0.021^{\mathrm{a}}$} \\
\hline Failed & $27(50 \%)$ & 9 & 18 & \\
\hline Total & $54(100 \%)$ & $35(64.8 \%)$ & $19(35.2 \%)$ & \\
\hline \multicolumn{2}{|c|}{ Sensitivity/specificity (\%) } & \multicolumn{3}{|c|}{$94.7 / 74.3$} \\
\hline
\end{tabular}

${ }^{\mathrm{a} M c N e m a r}$ test.

The screening is an examination aiming to determine whether or not a person is likely to have the investigated disorder. The usefulness of a screening should be evaluated against an independent standard; in audiology, this standard is the pure tone audiometry. ${ }^{35}$

Hearing screenings in older adults, however, have been the subject of few studies. Previous studies have reported the use of various methods, such as self-assessment questionnaires, $3,5,10,18,21,28$ tests using a tuning fork, ${ }^{5,22}$ the whispered voice test, ${ }^{3,5,22}$ the finger snapping test, ${ }^{3,35}$ tests using a single generic question, ${ }^{3,27}$ and tests using a portable audioscope (Welch Allyn Inc., Skaneateles Fall, New York, United States) device. ${ }^{3,5,22,28}$ Among these methods, the most reliable for screening hearing impairment involve the use of the audioscope, $5,22,29$ and the joint application of the Hearing Handicap Inventory for the Elderly instrument-reduced version-and the audioscope. ${ }^{22,29,30,36}$
The audioscope is similar to the equipment used in our study. It is an otoscope that emits pure tones at the frequencies of $500,1,000,2,000$, and $4,000 \mathrm{~Hz}$, at intensities of 20,25 , and $40 \mathrm{dBHL}$. Screening using this equipment does not require expertise in audiology and lasts approximately 3 minutes. ${ }^{36}$

The results obtained show that, by analyzing the responses of the hearing screening using criteria 1 , there was high specificity but low sensitivity (i.e., the equipment did not allow for the identification of individuals with mild to moderate hearing loss).

Considering this method of analyzing the results, sensitivity and specificity values were lower than with the audioscope. In a previous study, ${ }^{37}$ seniors had been screened in medical offices and at an audiological center. Sensitivity was identical in both locations (94\%) and specificity was lower in medical offices (72\%) when compared with the audiological center (90\%).

Table 3 Analysis of responses to hearing screening in left ear, considering the interpretation according to criteria 1 and 2

\begin{tabular}{|c|c|c|c|c|}
\hline & \multirow[t]{2}{*}{ Total } & \multicolumn{2}{|c|}{ Left ear hearing classification ${ }^{a}$} & \multirow[t]{2}{*}{$p$} \\
\hline & & Normal hearing & Hearing loss & \\
\hline \multicolumn{5}{|l|}{ Criteria 1} \\
\hline Passed & $52(94.5 \%)$ & 41 & 11 & \multirow[t]{2}{*}{$0.001^{\mathrm{a}}$} \\
\hline Failed & $3(5.5 \%)$ & 0 & 3 & \\
\hline Total & 55 (100\%) & $41(72.5 \%)$ & $14(25.5 \%)$ & \\
\hline \multicolumn{2}{|c|}{ Sensitivity/specificity (\%) } & \multicolumn{3}{|c|}{$21.4 / 100$} \\
\hline \multicolumn{5}{|c|}{ Criteria 2} \\
\hline Passed & $27(49.1 \%)$ & 27 & 0 & \multirow[t]{2}{*}{$0.001^{\mathrm{a}}$} \\
\hline Failed & $28(50.9 \%)$ & 14 & 14 & \\
\hline Total & 55 (100\%) & $41(74.5 \%)$ & $14(25.5 \%)$ & \\
\hline \multicolumn{2}{|c|}{ Sensitivity/specificity (\%) } & \multicolumn{3}{|c|}{$100 / 65.9$} \\
\hline
\end{tabular}

aMcNemar test. 
When using the new evaluation method proposed by the researchers (criteria 2), however, there was a significant increase in sensitivity, but a decrease in specificity was observed. With this new way of interpretation, the sensitivity values reached $94.7 \%$ in the right ear and $100 \%$ in the left ear. The values proved similar to those obtained with the audioscope, thus extending the possibility of identifying individuals with mild and moderate hearing loss, which usually occurs in presbycusis. However, this interpretation decreased specificity values, which was $100 \%$ for both ears using the manufacturer's criterion. With the new criterion, the specificity obtained was $74.3 \%$ for the right ear and $65.9 \%$ for the left ear, which means that the possibility of false-positives increased.

In diseases of high prevalence in the population, such as hearing loss, screening tests must have a high sensitivity to be useful to clinicians, because, otherwise, negative results may be false-negatives. ${ }^{38}$ False-negatives should be the main concern for the screening. When hearing loss goes undetected, individuals are not referred for assessment and diagnosis, which consequently prevents treatment from being initiated. Thus, the cutoff or criterion used must prioritize maximum sensitivity, ${ }^{24,38,39}$ because prioritizing greater specificity is likely to increase the number of false-negatives. ${ }^{5,7,8}$

Based on this premise, it is believed that the interpretation of results using the criterion set by the investigators is more effective and efficient for detecting hearing loss in adults and older adults. It is suggested, therefore, that professionals begin using this new criterion, thus reducing the possibility of false-negatives and ensuring that individuals with mild to moderate hearing loss are identified during hearing screening using portable equipment. It is important to reinforce that testing was performed considering individuals with normal hearing and with mild to moderate hearing loss. In these individuals, the method developed by the researchers was more appropriate, proving to have enough sensitivity to identify minimal hearing loss.

Therefore, it became clear that, provided the properly established criteria for analysis of the responses, this portable equipment possesses excellent usefulness in daily clinical practice, allowing middle-aged adults and older adult persons with hearing loss to be identified, referred for evaluation, and, if necessary, oriented on the use of hearing aids.

This study showed that, in the hearing screening of middleaged adults and older adults using portable equipment, the rules for interpreting results suggested by the manufacturer showed low sensitivity and high specificity in identifying mild to moderate hearing loss. However, the adoption of a new criterion developed by researchers increased the sensitivity, thus allowing individuals with such degrees of hearing loss to be identified. We concluded that, when using the proper methodology, hearing screening devices can be effective in screening for hearing loss in adults and older adult persons.

\section{References}

1 Onishi ET, Barreiro FCAB, Scharlach RC. Distúrbios da audição: implicações nas diferentes fases da vida. Saúde Coletiva 2011; 8:62-66
2 Gates GA, Mills JH. Presbycusis. Lancet 2005;366:1111-1120

3 Chou R, Dana T, Bougatsos C, Fleming C, Beil T. Screening adults aged 50 years or older for hearing loss: a review of the evidence for the U.S. preventive services task force. Ann Intern Med 2011; 154:347-355

4 Li-Korotky HS. Age-related hearing loss: quality of care for quality of life. Gerontologist 2012;52:265-271

5 Bagai A, Thavendiranathan P, Detsky AS. Does this patient have hearing impairment? JAMA 2006;295:416-428

6 Veras RP, Mattos LC. Audiologia do envelhecimento: revisão da literatura e perspectivas atuais. Rev Bras Otorrinolaringol (Engl Ed) 2007;73:128-134

7 Bance M. Hearing and aging. CMAJ 2007;176:925-927

8 Davis A, Smith P, Ferguson M, Stephens D, Gianopoulos I. Acceptability, benefit and costs of early screening for hearing disability: a study of potential screening tests and models. Health Technol Assess 2007;11:1-294

9 Baraldi GS, de Almeida LC, Borges ACC. Evolução da perda auditiva no decorrer do envelhecimento. Rev Bras Otorrinolaringol (Engl Ed) 2007;73:64-70

10 Samelli AG, Negretti CA, Ueda KS, Moreira RR, Schochat E. Comparação entre avaliação audiológica e screening: um estudo sobre presbiacusia. Braz J Otorhinolaryngol 2011;77:70-76

11 Francelin MAS, Motti TFG, Morita I. As implicações sociais da deficiência auditiva adquirida em adultos. Saúde e Sociedade 2010;19:180-192

12 Teixeira AR, Thedy RB, Jotz GP, de Barba MC. Depressive symptomatology in hearing impaired adults and elders: importance of the use of hearing aids. Intl Arch Otorhinolaryngol 2007;11:453-458

13 Cruz MS, Oliveira LR, Carandina L, et al. Prevalência de deficiência auditiva referida e causas atribuídas: um estudo de base populacional. Cad Saude Publica 2009;25:1123-1131

14 Saito H, Nishiwaki Y, Michikawa T, et al. Hearing handicap predicts the development of depressive symptoms after 3 years in older community-dwelling Japanese. J Am Geriatr Soc 2010;58:93-97

15 Boi R, Racca L, Cavallero A, et al. Hearing loss and depressive symptoms in elderly patients. Geriatr Gerontol Int 2012; 12:440-445

16 Kiely KM, Gopinath B, Mitchell P, Luszcz M, Anstey KJ. Cognitive, health, and sociodemographic predictors of longitudinal decline in hearing acuity among older adults. J Gerontol A Biol Sci Med Sci 2012;67:997-1003

17 Gates GA, Murphy M, Rees TS, Fraher A. Screening for handicapping hearing loss in the elderly. J Fam Pract 2003;52:56-62

18 Scudder SG, Culbertson DS, Waldron CM, Stewart J. Predictive validity and reliability of adult hearing screening techniques. J Am Acad Audiol 2003;14:9-19

19 Mattos LC, Veras RP. A prevalência da perda auditiva em uma população de idosos da cidade do Rio de Janeiro: um estudo seccional. Rev Bras Otorrinolaringol (Engl Ed) 2007;73:654-659

20 Fook L, Morgan R. Hearing impairment in older people: a review. Postgrad Med J 2000;76:537-541

21 Gordon-Salant S. Hearing loss and aging: new reseach findings and clinical implications. JRRD 2005;42(4, Suppl 2):9-24

22 Yueh B, Shapiro N, MacLean CH, Shekelle PG. Screening and management of adult hearing loss in primary care: scientific review. JAMA 2003;289:1976-1985

23 Bentur N, Valinsky L, Lemberger J, Benmosche Y, Heymann AD. Primary care intervention programme to improve early detection of hearing loss in the older adult. JLO 2012;126:574-579

24 American Speech-Language-Hearing Association. 1997. Guidelines for audiologic screening [accessed on October 21, 2012]. Available at: http://www.asha.org/docs/html/GL1997-00199. html\#sec1.9.1

25 Siemens [Internet]. Your hearing-simplified by HearCheck. [accessed on May 2012, 25] Available at: http://hearing.siemens.com/ Global/en/professional-area/workflow/hear-check/hear-check. html 
26 World Health Organization. WHO/PDH/97.3. Geneva, Switzerland: WHO: 1997. Available at: http://whqlibdoc.who.int/hq/1997/ WHO_PDH_97.3.pdf. Accesssed on May 25, 2012.

27 Eekhof JAH, De Bock GH, Schaapveld K, Springer MP. Effects of screening for disorders among the elderly: an intervention study in general practice. Fam Pract 2000;17:329-333

28 Valete-Rosalino CM, Rozenfeld S. Triagem auditiva em idosos: comparação entre auto-relato e audiometria. Rev Bras Otorrinolaringol (Engl Ed) 2005;71:193-200

29 Yueh B, Collins MP, Souza PE, et al. Screening for Auditory Impairment-Which Hearing Assessment Test (SAI-WHAT): RCT design and baseline characteristics. Contemp Clin Trials 2007; 28:303-315

30 Hidalgo JLT, Gras CB, Lapeira JMT, et al. The Hearing-Dependent Daily Activities Scale to evaluate impact of hearing loss in older people. Ann Fam Med 2008;6:441-447

31 Weinstein BE. Hearing loss in the older adult: a new look at an old problem. In: Katz J, ed. Handbook of Clinical Audiology. 6th ed. Philadelphia, PA: Wolters Kluwer/Lippincott Williams \& Wilkins; 2009:712-725

32 Carvalho JA, Rodríguez-Wong LL. A transição da estrutura etária da população brasileira na primeira metade do século XXI. Cad Saude Publica 2008;24:597-605
33 Calais LL, Borges ACLC, Baraldi GS, de Almeida LC. Queixas e preocupações otológicas e as dificuldades de comunicação de indivíduos idosos. Rev Bras Fonoaudiol 2008;13:12-19

34 Teixeira AR, Almeida LG, Jotz GP, de Barba MC. Qualidade de vida de adultos e idosos pós adaptação de próteses auditivas. Rev Soc Bras Fonoaudiol 2008;13:357-361

35 Torres-Russotto D, Landau WM, Harding GW, Bohne BA, Sun K, Sinatra PM. Calibrated finger rub auditory screening test (CALFRAST). Neurology 2009;72:1595-1600

36 Yueh B, Collins MP, Souza PE, et al. Long-term effectiveness of screening for hearing loss: the screening for auditory impairment -which hearing assessment test (SAI-WHAT) randomized trial. JAGS 2010;58:427-434

37 Lichtenstein MJ, Bess FH, Logan SA. Validation of screening tools for identifying hearing-impaired elderly in primary care. JAMA 1988;259:2875-2878

38 Fletcher RH, Fletcher SW, Wagner EH. Diagnóstico. In: Fletcher RH, Fletcher SW, Wagner EH. Epidemiologia Clínica: Elementos Essenciais. 3rd ed. Porto Alegre: Artes Médicas; 1996:52-83

39 Goulart BNG, Chiari BM. Testes de rastreamento x testes de diagnóstico: atualidades no contexto da atuação fonoaudiológica. Pro Fono 2007; 19:223-232 